\title{
educação

\section{Escala de Atribuições de Causalidade e Rendimento Escolar: Estudo de Evidência de Validade de Critério}

\author{
Adriana Satico Ferraz \& Acácia Aparecida \\ Angeli dos SAnTOS ${ }^{\text {II }}$ \\ Universidade São Francisco, Brasil
}

\author{
LEANDro S. Almeida III \\ Universidade do Minho, Portugal
}

\begin{abstract}
O objetivo deste estudo foi conferir a evidência de validade de critério concorrente para a Escala de Avaliação das Atribuições de Causalidade para Alunos do Ensino Fundamental (EAVAT-EF), tendo como variável critério o rendimento escolar. Considerou-se como medida de rendimento as classificações dos alunos em Língua Portuguesa e Matemática e a sua autopercepção de rendimento na escola. Participaram 661 alunos de escolas públicas brasileiras do Ensino Fundamental I e II $\left(3 .^{\circ}\right.$ ao $9 .^{\circ}$ ano), de ambos os gêneros, com idades entre 8 e 17 anos $(M=11.82 ; D P=1.91)$. O modelo de predição do rendimento escolar constituiu-se pelos fatores da EAVAT-EF acrescido às variáveis gênero, número de repetências e autopercepção de rendimento, e foi testado nos dois ciclos do Ensino Fundamental. Este modelo funcionou apenas para o Ensino Fundamental II. No Ensino Fundamental I, por meio da análise de regressão linear, os fatores da EAVAT-EF tiveram a variância explicada menos expressiva para o rendimento escolar em comparação aos coeficientes padronizados identificados no Ensino Fundamental II. Considera-se que as atribuições de causalidade têm impacto no rendimento escolar avaliado por meio das classificações e da autopercepção de rendimento dos alunos, e vice-versa. Os resultados sugerem, ainda, que este impacto se consolida, tornandose cada vez mais relevante com o avançar na escolaridade.
\end{abstract}

Palavras-chave: Atribuição causal; Motivação para a aprendizagem; Ensino Básico; Avaliação psicoeducacional

\section{N T RO D U Ç Ã O}

São recorrentes as discussões relativas ao rendimento escolar por parte dos profissionais atuantes nos campos da Psicologia e da
Educação, com especial atenção aos alunos que apresentam baixas classificações e àqueles que demonstram pouco interesse em participar nas atividades escolares. Ao discorrer sobre os aspectos inerentes ao rendimento escolar é 
importante considerar o papel da motivação do aluno para aprender, verificada na presente pesquisa sob a perspectiva da teoria das atribuições de causalidade intrapessoais, com o propósito de conferir a evidência de validade de critério concorrente para a Escala de Avaliação das Atribuições de Causalidade para Alunos do Ensino Fundamental (EAVAT-EF) (Boruchovitch \& Santos, 2013).

Este estudo considerou a parte cognitiva das atribuições de causalidade intrapessoais, relativa à interpretação do aluno sobre as causas subjacentes às situações de êxito e de fracasso escolar, principalmente em face ao rendimento na escola. Em linhas gerais, após vivenciar determinada situação, positiva ou negativa, o aluno recorre à atribuição de causas que a expliquem. Ao longo de suas pesquisas no contexto escolar, Weiner (1986, 2010, 2018) identificou quatro causas atribucionais principais, às quais os alunos recorrem para justificar as suas vivências na escola. Dentre elas, algumas são prevalentes, a saber: a capacidade/inteligência, o esforço, a dificuldade da tarefa e a sorte.

Ao identificar a causa atribucional para a situação vivenciada, o aluno a classifica de acordo com três dimensões que conferem um sentido psicológico às atribuições de causalidade, referentes ao lócus de causalidade, à estabilidade e à controlabilidade (Weiner, 1986, 2018). O lócus de causalidade pode ser classificado como mais interno ou externo e evidencia o quanto o aluno se responsabiliza ou não pelo ocorrido. A estabilidade é marcada pela noção do aluno acerca da possibilidade de a causa atribucional ser ou não suscetível a alterações ao longo do tempo, o que pode levar à motivação do aluno em situações similares a serem vivenciadas no futuro. A última dimensão se refere à controlabilidade, expressa pela percepção do nível de controle que o aluno acha que possui sobre a causa atribuída
(Almeida \& Guisande, 2010; Bzuneck, Boruchovitch, Miranda, \& Almeida, 2014; Lohbeck, Grube, \& Moschner, 2017; Paiva \& Boruchovitch, 2014; Weiner, 2010, 2018).

$\mathrm{Na}$ presente pesquisa foram consideradas como medidas de rendimento escolar as classificações dos alunos em Língua Portuguesa e Matemática. Esta escolha ocorreu por se tratarem de disciplinas básicas para a aprendizagem de diversas áreas do conhecimento ao longo da escolarização, como é o caso das Ciências Humanas, Biológicas e Exatas (Brasil, 1997a, 1997b). Vale destacar que elas são, também, avaliadas pelo Sistema de Avaliação da Educação Básica (SAEB), com a finalidade de verificar o desempenho dos alunos e a qualidade do ensino ofertado na Educação Básica do Brasil (Instituto Nacional de Estudos e Pesquisas Educacionais Anísio Teixeira [INEP], 2017). Além disso, a literatura aponta para a existência de investigações empíricas das atribuições de causalidade intrapessoais em razão dos resultados de êxito e fracasso na língua do país e na Matemática, uma vez que estas situações se associam à constituição das crenças atribucionais dos alunos ao longo do processo de escolarização (Bzuneck et al., 2014; Mijs, 2016; Miranda, Almeida, Boruchovitch, Almeida, \& Abreu, 2012; Zambon \& Rose, 2012).

A respeito das pesquisas sobre a temática aqui abordada, Neves e Faria (2007) identificaram que alunos portugueses do 9..$^{\circ}$ e $10 .^{\circ}$ ano atribuíram o alto desempenho em Língua Portuguesa e Matemática às atribuições de causalidade mais internas, controláveis e estáveis, como fazer os trabalhos extracurriculares, prestar atenção nas aulas, interessar-se pela disciplina e participar nas aulas. Diferentemente, alunos com baixo rendimento indicaram atribuições de causalidade mais externas e incontroláveis, como a dificuldade dos testes. Miranda et al. 
(2012) encontraram correlações positivas e moderadas entre a capacidade atribuída pelos alunos ao bom desempenho em português e matemática, enquanto que a falta de capacidade esteve correlacionada ao fraco desempenho em ambas as disciplinas. Por sua vez, Erten e Burden (2014) identificaram que o desempenho em Inglês de alunos turcos esteve associado com a valorização do professor, de lócus de causalidade externo e incontrolável. Todavia, como fomos documentando, é de incluir também a percepção de capacidade e o interesse, ambos de lócus de causalidade internos, sendo o primeiro incontrolável e o segundo controlável, bem como o esforço de longo prazo, compreendido como controlável e estável. Os alunos com melhor desempenho referem mais estas causas do que os alunos com baixo desempenho.

Com o intuito de avaliar as atribuições de causalidade voltadas ao fracasso em Matemática, Mijs (2016) controlou as variáveis gênero, idade, nível socioeconômico, dentre outras, e dividiu os alunos de 24 países que realizaram o Programme for International Student Assessment (PISA) em conformidade com as práticas educacionais a que eram submetidos. Por meio da análise multinível, o autor identificou que a sensação de culpa em decorrência da atribuição do aluno à falta de capacidade (lócus de causalidade interna e incontrolável) foi preditora do fracasso em Matemática nos grupos em que o desempenho escolar estava associado ao esforço e às habilidades do aluno. Por sua vez, no grupo de alunos submetidos às práticas mistas, que enfatizavam, além da habilidade e esforço do aluno, a participação dos professores e da família, as atribuições de causalidade relativas ao apoio insuficiente do professor e à falta de sorte (lócus de causalidade externo e incontrolável) foram preditoras do insucesso. Os resultados obtidos pelo autor sugerem que as configurações do ambiente de ensino e aprendizagem interferem nas atribuições de causalidade do aluno.

Ao abordar o rendimento escolar é igualmente importante considerar a autopercepção do aluno acerca do seu desempenho na escola, pois a autoavaliação é inerente ao processo do autojulgamento do aluno (Weiner, 2010; Zimmerman, 2013). Além disto, pode auxiliar a compreensão acerca do impacto de suas classificações na motivação para aprender (Dalbosco, Ferraz, \& Santos, 2018). Neste sentido, Guimarães (2009) e Pereira (2015) consideram que as comparações feitas em sala de aula, quando restritas somente aos resultados das avaliações, podem promover, por um lado, uma supervalorização dos alunos com classificações mais altas, e, por outro, aqueles que apresentam classificações mais baixas são desvalorizados. Os alunos que são frequentemente expostos em sala de aula devido ao seu baixo rendimento e que não recebem devolutivas que os orientem a superar as suas dificuldades tendem a se sentir inferiores e incapazes. Em decorrência, apresentam diminuição do esforço e persistência, aspectos estes que se tornam fontes da desmotivação para aprender (Almeida \& Guisande, 2010; Boruchovitch \& Bzuneck, 2010; Ferraz, Cantalice, \& Santos, no prelo).

Para investigar a evidência de validade de critério concorrente, analisou-se no presente estudo a variância explicada dos fatores da EAVAT-EF para o rendimento escolar do aluno. A este modelo foram acrescidas como variáveis independentes o gênero, o número de repetências e a autopercepção de rendimento escolar do aluno. O modelo foi testado nos dois ciclos do Ensino Fundamental, correspondendo a alunos entre as idades de 8 e 10 anos e entre 11 e 14 anos, respetivamente.

A inclusão da variável gênero ao modelo proposto fundamentou-se em resultados de 
pesquisas anteriores que identificaram que as meninas apresentavam melhor rendimento na escola, tanto em termos das suas classificações como em medidas 'indiretas' do rendimento escolar (e. g., compreensão de leitura) (Osti \& Martinelli, 2014; Rosander \& Bäckström, 2012; Suehiro \& Boruchovitch, 2016). Em relação às atribuições de causalidade, as meninas aparentam maior predisposição para indicar causas de lócus de causalidade internos, tanto para a situações de fracasso (e.g., falta de capacidade) como de sucesso (e.g., esforço) (Dickhäuser \& Meyer, 2006; Lohbeck et al., 2017; McClure et al., 2011).

Ademais, o acréscimo do número de repetências na composição dos modelos testados fundamentou-se em algumas investigações que apontam para o impacto do histórico de rendimento do aluno na sua autoestima e comportamentos escolares (Costa \& Boruchovitch, 2010; Nascimento \& Peixoto, 2012). Com crianças brasileiras, Costa e Boruchovitch (2010) verificaram maior dificuldade de administrar o tempo e a falta de compromisso com os estudos nos alunos repetentes, experienciando ainda maior insegurança em expor os seus conhecimentos e o receio de fracassar. Nesse sentido, os comportamentos de procurar ajuda e se concentrar na figura do professor (apoio social), identificados por Costa e Boruchovitch (2010), podem estar ligados às crenças atribucionais de lócus de causalidade mais externas e incontroláveis, conforme foi identificado posteriormente nos estudos de Paiva e Boruchovitch (2010) e Garcia e Boruchovitch $(2014,2015)$, com amostras de alunos brasileiros retidos dos dois ciclos do Ensino Fundamental.

Por último, levantaram-se como hipóteses para o modelo proposto no presente estudo as possíveis diferenças existentes entre os dois ciclos do Ensino Fundamental, uma vez que parece haver mudanças na qualidade motivacional do aluno em decorrência da transição do primeiro para o segundo nível de ensino. O impacto das atribuições de causalidade, assim como do gênero, do histórico de repetência e da autopercepção no rendimento escolar é variável ao longo da escolaridade e do desenvolvimento psicossocial dos alunos. Todavia, também o contato do aluno com o ambiente escolar, que abarca as suas vivências de sucesso/fracasso e o tratamento que lhes é conferido pelos professores e seus pares, pode determinar as razões ou as atribuições causais a que os alunos recorrem para explicar o seu rendimento (Bzuneck et al., 2014; Lohbeck et al., 2017).

\section{MÉ T O DO}

\subsection{PARTICIPANTES}

O estudo contou com a participação de 661 alunos dos dois ciclos do Ensino Fundamental matriculados em seis escolas públicas situadas no interior do estado de São Paulo, sendo 351 meninas $(53.1 \%)$ e 310 meninos (46.9\%). Do primeiro ciclo do Ensino Fundamental (3. ${ }^{\circ}$ ao 5. ano) participaram 238 alunos (36\%), com idades entre 8 e 13 anos $(\mathrm{M}=9.83$; $\mathrm{DP}=$ 1.08). Dentre estes alunos, 19 repetiram uma vez e quatro deles duas vezes. Do segundo ciclo do Ensino Fundamental (6..$^{\circ}$ ao $9 .^{\circ}$ ano), participaram 423 alunos (64\%), com idades entre 11 e 17 anos $(\mathrm{M}=12.95$; $\mathrm{DP}=1.23)$, sendo que 56 repetiram uma vez, 12 duas vezes e cinco deles três vezes.

\subsection{INSTRUMENTOS}

\section{QuestionáRIO SOCIODEMOGRÁFICO}

Este questionário foi elaborado por Boruchovitch e Santos (2013) no âmbito do instrumento EAVAT-EF, com a finalidade de caracterizar cada participante. Foram 
coletadas informações relativas a idade, ano escolar, gênero e existência de histórico de repetência. As autoras e autor do presente estudo incluíram neste espaço a orientação para o aluno atribuir uma classificação a si mesmo. Para isto, solicitou-se ao aluno que assinalasse uma nota numa classificação de 0 a 10 pontos.

ESCALA DE AVALIAÇÃO DAS ATRIBUIÇÕES DE CAUSALIDADE PARA ALUNOS DO ENSINO FUNDAMENTAL (EAVAT-EF) (BORUCHOVITCH \& SANTOS, 2013 )

Este instrumento destina-se à avaliação das atribuições de causalidade em alunos dos dois ciclos do Ensino Fundamental. A EAVAT-EF possui 35 itens, divididos em dois fatores. $\mathrm{O}$ Fator 1, referente às Causas para o Sucesso (17 itens - itens 1 ao 17) e o Fator 2, Causas para o Fracasso (18 itens - itens 18 ao 35). Na EAVATEF o fracasso é atribuído às causas externas e de pouco controle e o sucesso é atribuído às causas internas e de maior controle pelo aluno. As atribuições de causalidade avaliadas pela EAVAT-EF são a capacidade/inteligência, prestar ou não atenção, esforço, dificuldade da tarefa e sorte. Exemplo de item do fator 1: "Tiro boas notas porque sou inteligente" (atribuição de causalidade: inteligência - lócus de causalidade interna e incontrolável). Exemplo de item do fator 2: "Sou um mau aluno porque as matérias são difíceis para mim" (atribuição de causalidade: dificuldade da tarefa - lócus de causalidade externa e incontrolável).

As respostas são dadas numa escala tipo Likert, com três opções: "sempre", "às vezes" e "nunca", com pontuação 3,2 e 1, respectivamente. Os escores correspondem à média ponderada das pontuações dos itens na escala de 3 pontos usada (valor intermédio de 1,5 pontos, sendo a pontuação mínima de 1 e a máxima de 3 pontos). Todos os itens do fator Causas para o Fracasso requerem a sua inversão (Boruchovitch \& Santos, 2015). Altas pontuações nos fatores Causas para o Sucesso e Causas para a Fracasso sugerem atribuições de causalidade mais internas e controláveis, enquanto que baixas pontuações em ambos os fatores são indicativos de atribuições de causalidade mais externas e percebidas como incontroláveis.

Em relação às propriedades psicométricas do instrumento, Boruchovitch e Santos (2015) verificaram índices de consistência interna adequados, com base no coeficiente alfa de Cronbach, para uma amostra de alunos do Ensino Fundamental I e II $\left(3 .^{\circ}\right.$ ao $9 .^{\circ}$ ano) de escolas públicas do interior de São Paulo (EAVAT total $\alpha=0.91$; Fator $1, \alpha=0.92$; e Fator $2, \alpha=0.83)$. Para a amostra do presente estudo, a consistência interna do instrumento, obtida por meio do coeficiente alfa de Cronbach, se mostrou satisfatória (índices acima de 0,70, conforme Urbina, 2007), tanto em termos dos fatores Causas para o Sucesso (que apresentou $\alpha=0.83)$ e Causas para o Fracasso $(\alpha=0.82)$, como para a EAVAT-EF total $(\alpha=0.86)$.

\subsection{PROCEDIMENTOS DE COLETA DE D A D O S}

Para a execução do estudo foram seguidos os procedimentos éticos em pesquisa com seres humanos previstos pela Resolução CNS 510/2016 do Conselho Nacional de Saúde (Brasil, 2016), o que englobou a sua aprovação no Comitê de Ética e Pesquisa da universidade vinculada ao mesmo (CAAE: 73412917.6.0000.5514). Participaram do estudo apenas os alunos que trouxeram o Termo de Consentimento Livre e Esclarecido (TCLE) assinado pelos pais/responsáveis, sendo que os alunos com 12 anos ou mais também leram e assinaram o Termo de Assentimento Livre e Esclarecido (TALE). A aplicação da EAVATEF foi realizada em sala de aula, coletivamente, 
sendo que os alunos demoraram em média 15 minutos para preencher.

Após a recolha do teste, foram excluídos da pesquisa os protocolos dos alunos que recebiam auxílio de monitores, em decorrência do diagnóstico de transtorno global do desenvolvimento (autismo, $n=$ 2) e com deficiência (deficiência visual, $n$ $=1$ e deficiência auditiva, $n=2$ ). Tomouse esta medida com o objetivo de eliminar a interferência destes monitores nas respostas dos alunos. Também foram descartados os protocolos dos alunos que desistiram de responder ao teste $(n=9)$. Os participantes excluídos da pesquisa não entraram na caracterização da amostra do presente estudo. As classificações dos alunos em Língua Portuguesa e Matemática, referentes ao bimestre em que os alunos participaram da pesquisa, foram solicitadas às secretarias de cada escola.

\subsection{ANÁLISE DE DADOS}

Verificou-se a normalidade dos dados por meio da distribuição da assimetria e da curtose, que atenderam aos valores situados entre -2 e 2 , conforme recomendado por Field (2009) para amostras com 200 ou mais sujeitos. Os dados foram analisados por meio do software MPlus, versão 7, a fim de testar o modelo proposto por meio da modelagem de equações estruturais (Muthén \& Muthén, 2012). Consideraramse como índices o Root Mean Square Error of Approximation (RMSEA), que estipula como um bom ajuste valores abaixo de 0.05; o Confirmatory Fit Index (CFI) e o Tucker-Lewis Index (TLI) com valores iguais ou superiores a 0.90 (Kline, 2011). Utilizou-se o software Statistical Package for Social Sciences (SPSS) versão 22.0, para gerar as análises descritivas e de frequência voltadas à caracterização da amostra; verificação de médias e desvios- padrão da EAVAT-EF; análise de consistência interna dos dois fatores da EAVAT-EF a partir do coeficiente alfa de Cronbach e a análise de correlação $r$ de Pearson entre as classificações dos alunos em Língua Portuguesa e Matemática. As classificações dos índices de magnitude das correlações basearam-se em Dancey e Reidy (2006). Efetuou-se, ainda, uma análise de regressão linear com o método enter, em que os índices residuais do teste de Durbin-Watson situados entre 1.5 e 2 foram considerados como medida de confiabilidade ao modelo (Field, 2009).

\section{RESULTAD OS}

Primeiramente verificaram-se as médias e desvios-padrão dos fatores da EAVAT-EF nos dois ciclos do Ensino Fundamental. No primeiro ciclo, os alunos obtiveram no fator Causas para o Sucesso $M=2,33(\mathrm{DP}=0,32) \mathrm{e}$ no fator Causas para o Fracasso $M=2.59$ (DP $=0.30)$. No segundo ciclo, as Causas para o Sucesso apresentaram $M=2,19(\mathrm{DP}=0.33)$ e as Causas para o Fracasso $M=2.57(\mathrm{DP}=0.30)$. Estes índices aproximam-se do valor máximo que se pode atingir no instrumento (3 pontos), indicando que em ambos os ciclos os alunos demonstraram atribuições de causalidade mais internas e controláveis para explicarem o seu sucesso e fracasso escolar.

Em vias de compor a medida de rendimento escolar, primeiramente verificou-se a correlação existente entre as classificações dos alunos em Língua Portuguesa e Matemática. $\mathrm{O}$ índice de correlação obtido por meio do $r$ de Pearson foi estatisticamente significativo, positivo e de forte magnitude, $r=0.70$ ( $p<$ 0.001). Em razão desta associação, optou-se por uma medida única de rendimento escolar obtida pela média proveniente da soma das classificações de ambas as disciplinas.

Por conseguinte, a aplicação da modelagem 
de equações estruturais incluiu os dois fatores da EAVAT-EF (Causas para o Sucesso e Causas para o Fracasso), o gênero, o número de repetências e a autoavaliação de rendimento como preditores do rendimento escolar (variável dependente). Este modelo foi testado separadamente nos dois ciclos do Ensino Fundamental. Os índices gerados para o Ensino Fundamental $\mathrm{I}$ foram CFI = 0.832 , TLI $=0.411$ e RMSEA $=0.139($ IC 90\% 0.085 - 0.199); e, para o Ensino Fundamental II, CFI $=0.985$, TLI $=0.949$ e RMSEA $=0.06$ (IC \% $0.002-0.110$ ). Pelos índices gerados na análise verificou-se a comprovação do modelo proposto apenas para o segundo ciclo do Ensino Fundamental, ilustrado na Figura 1.

Conforme apresentado na Figura 1, no segundo ciclo do Ensino Fundamental, as atribuições de causalidade interferiram no rendimento escolar do aluno, especialmente no fator da EAVAT-EF Causas para o Sucesso $(\beta=$ 1.106). Com base nestes resultados, verificouse que, em ambas as situações - de sucesso e de fracasso -, as atribuições de causalidade foram classificadas como internas e controláveis.
Assim, identificou-se que, quando o aluno se responsabiliza pelas causas e se percebe como tendo controle sobre elas, há uma contribuição positiva para o seu rendimento escolar.

O gênero e o número de repetências também se mostraram como variáveis preditoras do rendimento escolar $(\beta=0.628 ; \beta=0.593$, respectivamente). Conforme exposto na Tabela 1 , as alunas tiveram resultados superiores aos alunos, bem como os alunos sem histórico de repetência escolar face aos colegas com três retenções. Congruentemente com estes resultados, ambas as variáveis foram preditoras da autoavaliação feita pelo aluno em relação ao seu rendimento na escola (gênero: $\beta=0.621$; número de repetências: $\beta=-0.419)$. Também se verifica (Tabela 1) que as alunas apresentaram maior autopercepção de rendimento do que os alunos, assim como os alunos sem histórico de repetência face aos colegas que reprovaram três vezes na escola.

Por último, a autopercepção de rendimento na escola se mostrou preditora, tanto do fator da EAVAT-EF Causas para o Sucesso $(\beta=$ 0.093) como do fator Causas para o Fracasso

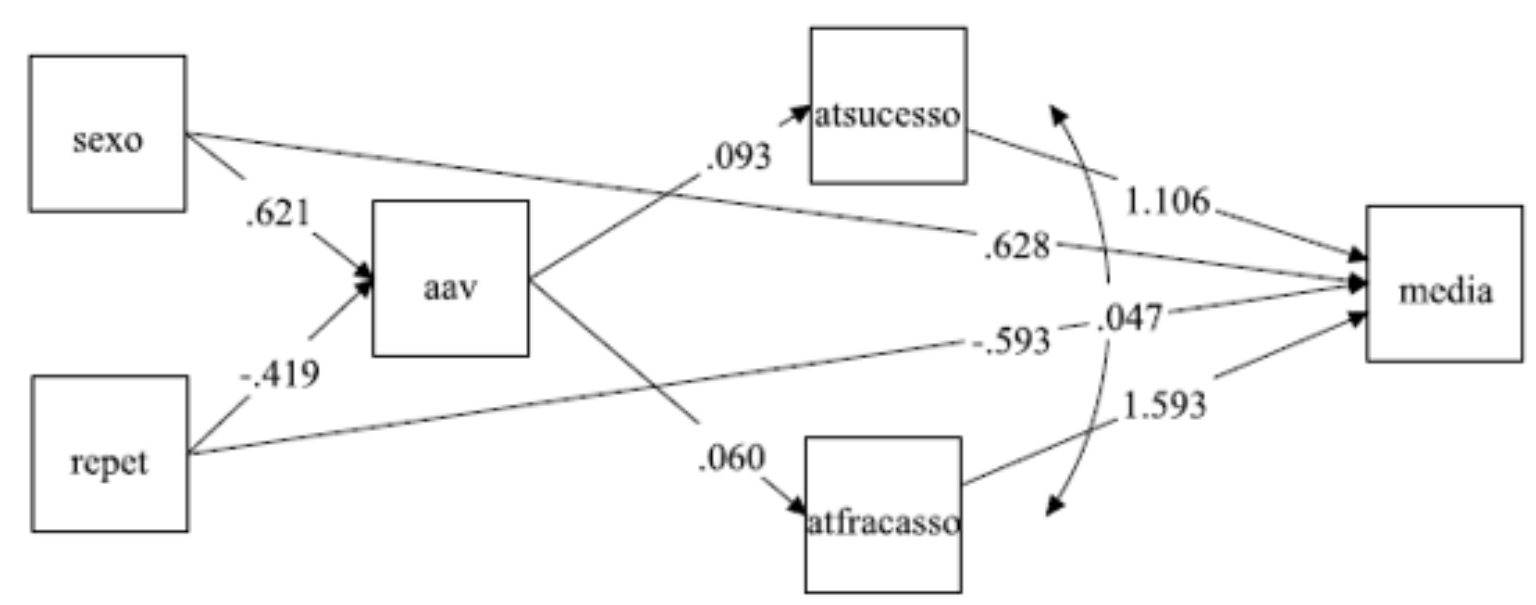

FIGURA 1. Modelagem de equações estruturais - variáveis independentes: EAVAT-EF, gênero, número de repetências e autoavaliação de rendimento; variável dependente: rendimento escolar. 
TABELA 1

Estatísticas Descritivas para o Rendimento Escolar e Autoavaliação do Rendimento em Razão do Gênero e Número de Repetências

\begin{tabular}{cccccc}
\hline Gênero e rendimento escolar & $N$ & Min. & Max. & $M$ & $D P$ \\
\hline Meninos & 197 & 3 & 9,75 & 6,06 & 1,54 \\
Meninas & 226 & 3 & 10 & 6,96 & 1,50 \\
\hline N. ${ }^{\circ}$ de repetências e rendimento & $N$ & Min. & Max. & $M$ & $D P$ \\
escolar & & & & & \\
\hline $\begin{array}{c}\text { Nenhuma vez } \\
\text { Uma vez }\end{array}$ & 308 & 3 & 10 & 6,77 & 1,59 \\
Duas vezes & 56 & 4 & 9,50 & 5,62 & 1,29 \\
Três vezes & 12 & 3 & 7,50 & 4,92 & 1,28 \\
Gênero e autoavaliação de & 5 & 3,50 & 5 & 4,70 & 0,67 \\
rendimento & $N$ & Min. & Max. & $M$ & $D P$ \\
\hline Meninos & & & & & \\
Meninas & 197 & 0 & 10 & 7,66 & 1,67 \\
\hline N. ${ }^{\circ}$ de repetências e autoavaliação de & 226 & 4 & 10 & 8,33 & 1,17 \\
rendimento & $N$ & Min. & Max. & $M$ & $D P$ \\
\hline Nenhuma vez & 308 & 0 & 10 & 8,08 & 1,30 \\
Uma vez & 56 & 1 & 10 & 7,46 & 2,04 \\
Duas vezes & 12 & 5 & 10 & 7,50 & 1,38 \\
Três vezes & 5 & 5 & 7 & 6,20 & 1,09 \\
\hline
\end{tabular}

$(\beta=0.06)$. Este resultado indica que, com o avançar dos anos escolares, o aluno tende a se autoavaliar em conformidade com as suas atribuições de causalidade, principalmente no que se refere às atribuições causais para o sucesso escolar.

Considerando que o modelo proposto não se ajustou no primeiro ciclo do Ensino Fundamental, procedeu-se à exploração das relações existentes entre as variáveis e o rendimento do aluno. Para esta análise recorreu-se à análise de regressão linear (método enter) a fim de compreender a contribuição das atribuições de causalidade intrapessoais para o rendimento escolar neste nível de ensino. Assumiram-se como variáveis independentes os dois fatores da EAVAT-EF, o gênero, o número de repetências e a autopercepção de rendimento do aluno, e, como variável dependente, o rendimento escolar. Os índices gerados nesta análise são expostos na Tabela 2.

TAB ELA 2

Coeficientes de Regressão entre a EAVAT-EF, Gênero, Número de Repetências, Autopercepção de Rendimento e o Rendimento Escolar

\begin{tabular}{ccccc}
\hline $\begin{array}{c}\text { Variável } \\
\text { dependente }\end{array}$ & Variável explicativa & $\beta$ & $p$ & $R^{2}$ ajustado \\
\hline & Causas para o Sucesso & 0,340 & 0,01 & \\
Rendimento & Causas para o Fracasso & 0,222 & 0,01 & \\
escolar & Gênero & 0,035 & 0,54 & 0,23 \\
& $\mathrm{~N} .{ }^{\circ}$ de repetências & 0,001 & 0,99 & \\
& Autopercepção de rendimento & 0,109 & 0,06 & \\
\hline
\end{tabular}


De acordo com a Tabela 2, observou-se que no primeiro ciclo do Ensino Fundamental os fatores da EAVAT-EF foram os únicos aspectos que apresentaram índices estatisticamente significativos, com $23 \%$ da variância explicada $(F=14.986[5,232], p<0.001)$. A maior contribuição para o rendimento escolar foi do fator Causas para o Sucesso, com valor $\beta=0.340(p<0.01)$. A correlação residual obtida pelo teste Durbin-Watson foi de 1.604, o que confere confiabilidade aos índices. Estes resultados sugerem que, nesse nível da escolarização, as atribuições de causalidade intrapessoais, em especial para as situações de êxito, foram os aspectos que interferiram no rendimento escolar. As variáveis gênero, número de repetências e a autopercepção de rendimento escolar do aluno não apresentaram variância explicada que fosse estatisticamente significativa para o rendimento escolar.

\section{D IsCUSS Ão}

Tendo como objetivo conferir evidência de validade de critério concorrente à EAVAT-EF, o rendimento escolar esteve positivamente associado às atribuições de causalidade internas, sendo estas mais ou menos controláveis, de acordo com as suas especificidades (e. g., esforço e capacidade) (Neves \& Faria, 2007; Miranda et al., 2012; Paiva \& Boruchovitch, 2010; Zambon \& Rose, 2012). É importante enfatizar que ao avaliar as atribuições de causalidade deve-se considerar as diferenças existentes entre os ciclos que compõem o Ensino Básico, de forma a verificar com maior precisão o funcionamento desta abordagem motivacional. Procedimento similar de análise foi adotado por Miranda et al. (2012), em seu estudo com alunos portugueses. Os autores identificaram que a atribuição à capacidade se correlacionou positivamente com o rendimento escolar, com índice mais expressivo no Ensino Básico (equivalente ao Ensino Fundamental II do Brasil) do que no Ensino Secundário (equivalente ao Ensino Médio). Os resultados de Miranda et al. (2012) convergem, em parte, com os do presente estudo, pois são indicativos de que os alunos do Ensino Fundamental II tendem a indicar atribuições de lócus de causalidade mais internas e demonstrar certo nível de controle da causa.

A variância explicativa das atribuições de causalidade para o rendimento escolar foi maior para o Ensino Fundamental II e o modelo proposto não funcionou para o Ensino Fundamental I. Conjectura-se que a existência de distinções de ordem cognitiva e psicológica, assim como na configuração dos contextos educacionais de cada um desses níveis de ensino, tenha sido responsável por esta diferença. Entende-se que estes dois aspectos interferem na compreensão e expressão das atribuições de causalidade intrapessoais, aliados às diferenças entre os gêneros e ao impacto na motivação para aprender em decorrência do número de retenções dos alunos do Ensino Fundamental II, tal como proposto no modelo testado (Bzuneck et al., 2014; Martinek \& Grifith, 1994; Nascimento \& Peixoto, 2012). Outros pontos que não foram analisados neste estudo, e que podem estar associados à constituição das crenças atribucionais nos alunos em relação ao rendimento escolar e à autopercepção de rendimento, dizem respeito às diferenças de idade, ao papel do professor, à organização da sala de aula e às metas de realização adotadas pelos alunos (Almeida \& Guisande, 2010; Brasil, 2017; Martinek \& Grifith, 1994; Mijs, 2016; Paiva \& Boruchovitch, 2010; Zambon \& Rose, 2012).

Os alunos do Ensino Fundamental II parecem demonstrar maior consciência sobre as suas atribuições de causalidade do que os alunos do Ensino Fundamental I, quando estabelecem 
relações entre este construto motivacional e os seus resultados escolares (Erten \& Burden, 2014; Martini \& Del Prette, 2005; Miranda et al., 2012). Sob esta perspectiva, as crenças positivas para a aprendizagem expressas por atribuições de lócus de causalidade internas, e principalmente por meio da noção do esforço, são importantes elementos para o bom rendimento escolar, pois sustentam a possibilidade de aprimoramento e de superação do baixo rendimento (Wagner, Spratt, Gal, \& Paris, 1989). Salienta-se, ainda, que as atribuições de causalidade mais internas tendem a se associar a percepções de autoestima e de autoconceito, assim como a maiores níveis de resiliência dos alunos para enfrentarem as suas dificuldades escolares (Garcia \& Boruchovitch, 2014; Nascimento \& Peixoto, 2012; Paiva \& Boruchovitch, 2010).

De acordo com o modelo proposto, identificaram-se, ainda, diferenças no rendimento escolar e na autopercepção de rendimento entre os gêneros e ligadas ao número de repetências, nos alunos do Ensino Fundamental II. O fato de as meninas demonstrarem rendimento superior ao dos meninos já foi identificado anteriormente, conforme descrevem os estudos de Osti e Martinelli (2014), Rosander e Bäckström (2012) e Suehiro e Boruchovitch (2016). Não obstante, vale destacar que a amostra de alunos repetentes do presente estudo era composta em grande parte por meninos, o que pode estar relacionado com a apresentação de médias mais baixas em relação às meninas. Situação análoga é reportada por Osti e Martinelli (2014), ao identificarem que os meninos, em desvantagem relativamente às meninas, no rendimento escolar, eram justamente aqueles que compunham o grupo de alunos com problemas de aprendizagem - é importante ressaltar que no estudo de Osti e Martinelli (2014) não foi investigada a associação entre a repetência e o rendimento escolar, portanto os resultados identificados por estas autores e os achados do presente estudo não se caracterizam como situações sinônimas.

O menor nível de rendimento escolar dos alunos que possuíam maior número de repetências parece revelar o impacto negativo nas atribuições de causalidade em consequência das experiências consecutivas de fracasso vivenciadas ao longo dessas retenções (Nascimento \& Peixoto, 2012; Schwerdt, West, \& Winters, 2017). Isto pode ser confirmado pela forma de eles se autoavaliarem, visto que as classificações por eles atribuídas a seu próprio rendimento foram diminuindo à medida que o número de repetências aumentava. Mediante estes resultados se faz necessário o desenvolvimento de outros estudos, centralizados especificamente na repercussão do número de repetências para a motivação do aluno, fundamentado na hipótese de as reprovações sucessivas interferirem negativamente na percepção pessoal e interpessoal de competência do aluno (INEP, 2016; Nascimento \& Peixoto, 2012; Paiva \& Boruchovitch, 2010; Schwerdt et al., 2017).

Além de conferir a evidência de validade de critério concorrente à EAVAT-EF, o presente estudo abre a perspectiva de investigação de outros aspectos associados à motivação para a aprendizagem em estudos futuros. Nesse sentido, destaca-se a relevância de também se avaliar as atribuições de causalidade interpessoais, com o objetivo de investigar o impacto do julgamento de professores e pessoas próximas ao aluno (e.g., colegas e pais) sobre o seu rendimento na escola (Dickhäuser \& Meyer, 2006). Com isso espera-se ampliar o conhecimento sobre a constituição das crenças atribucionais do aluno que, como constatado no presente estudo e em outras pesquisas, estão diretamente associadas ao rendimento 
e ao sucesso escolar (Paiva \& Boruchovitch, 2014).

Reconhece-se como limitação deste estudo a aplicação da EAVAT-EF em alunos de uma única região do Brasil, o que requer ampliação da amostra em pesquisas futuras. Assim, poderá ser constatado se a evidência de validade aqui identificada pode ou não ser generalizada às demais regiões do país (American Educational Research Association, American Psychological Association, \& National Council on Measurement in Education, 2014). Outra limitação diz respeito à composição da medida de rendimento escolar, visto que a sua extensão para as disciplinas de Artes e Educação Física, que estimulam importantes aspectos inerentes à motivação (e. g., criatividade e autonomia), poderia agregar mais informações sobre as atribuições de causalidade intrapessoais (Stader \& Licht, 1992). Em relação à autopercepção de rendimento na escola, seria interessante que os alunos se avaliassem tomando separadamente as disciplinas diferenciadas do seu currículo, com a finalidade de garantir maior precisão e objetividade a este tipo de avaliação. Em termos práticos, considera-se que a utilização da EAVAT-EF por psicólogos e educadores pode consistir em um recurso que viabiliza a compreensão acerca do modo como os seus alunos interpretam as experiências de sucesso e fracasso na escola. Este tipo de avaliação oferece, ainda, subsídios para a elaboração de intervenções que corroborem o desenvolvimento de crenças atribucionais mais funcionais e favoráveis ao rendimento escolar.

\section{AgRA DECIMENTOS}

A primeira autora agradece o financiamento desta pesquisa à Fundação de Amparo à Pesquisa do Estado de São Paulo (FAPESP), referente à Bolsa no país, processo n. ${ }^{\circ}$
2017/01370-7, e Bolsa de Estágio no Exterior (BEPE), processo n. ${ }^{\circ}$ 2017/21441-6.

Os autores agradecem as orientações e auxílio do Prof. Doutor Nelson Hauck, da Universidade São Francisco, Campus de Campinas, no tratamento dos dados deste estudo.

\section{REFERÊ NCIAS}

Almeida, L. S., \& Guisande, M. A. (2010). Atribuições causais na explicação da aprendizagem escolar. In E. Boruchovitch, J. A. Bzuneck, \& S. E. R. Guimarães (Orgs.), Motivação para aprender: Aplicações no contexto educativo (pp. 145-168). Petrópolis, RJ, Brasil: Vozes.

American Educational Research Association, American Psychological Association, \& National Council on Measurement in Education. (2014). Standards for educational and psychological testing. Washington, DC: American Educational Research Association.

Boruchovitch, E., \& Bzuneck, J. A. (2010). Motivação para aprender no Brasil: Estado da arte e caminhos futuros. In E. Boruchovitch, J. A. Bzuneck, \& S. E. R. Guimarães (Orgs.), Motivação para aprender: Aplicações no contexto educativo (pp. 231-250). Petrópolis, RJ, Brasil: Vozes.

Boruchovitch, E., \& Santos, A. A. A. (2013). Escala de Avaliação das Atribuições de Causalidade para Sucesso e Fracasso Escolar. Manuscrito não publicado. Universidade Estadual de Campinas, Campinas, SP.

Boruchovitch, E., \& Santos, A. A. A. (2015). Escala de Atribuições de Causalidade de Estudantes do Ensino Fundamental (EAVAT-EF). Interação em Psicologia, 19(3), 395-406. doi:10.5380/psi.v19i3.35635

Brasil, Conselho Nacional de Saúde. (2016). Resolução CNS 510, de 07 de abril de 2016. 
Recuperado de http://conselho.saude.gov. br/resolucoes/2016/Reso510.pdf

Brasil, Ministério da Educação. (1997a). Parâmetros Curriculares Nacionais: Língua Portuguesa. Recuperado de http://portal. mec.gov.br/seb/arquivos/pdf/livro02.pdf

Brasil, Ministério da Educação. (1997b). Parâmetros Curriculares Nacionais: Matemática. Recuperado de portal.mec.gov. br/seb/arquivos/pdf/livro03.pdf

Brasil, Ministério da Educação. (2017). Base Nacional Comum Curricular. Recuperado de http://basenacionalcomum.mec.gov.br/

Bzuneck, J. A., Boruchovitch, E., Miranda, L., \& Almeida, L. S. (2014). Motivação acadêmica dos alunos. In L. S. Almeida \& A. M. Araújo (Eds.), Aprendizagem e sucesso escolar: Variáveis pessoais dos alunos (pp. 173-214). Braga, Portugal: ADIPSIEDUC.

Costa, E. R. D., \& Boruchovitch, E. (2010). As estratégias de aprendizagem de alunos repetentes do ensino fundamental. Psicologia em Pesquisa, 4(1), 31-39.

Dalbosco, S. N. P., Ferraz, A. S., \& Santos. A. A. A. (2018). Metas de realização, autorregulação da aprendizagem e autopercepção de desempenho em universitários. Revista Brasileira de Orientação Profissional, 19(1), 75-84. doi:1026707/1984-7270/2019v19n1p75

Dancey, C. P., \& Reidy, J. (2006). Estatística sem matemática para psicólogos. Porto Alegre, RS, Brasil: Artes Médicas.

Dickhäuser, O., \& Meyer, W. (2006). Gender differences in young children's math ability attributions. Psychology Science, 48, 3-16.

Erten, İ. H., \& Burden, R. L. (2014). The relationship between academic self-concept, attributions, and L2 achievement. System, 42, 391-401. doi:10.1016/j.system.2014.01.006

Ferraz, A. S., Cantalice, L. M., \& Santos, A. A. A. (no prelo). Motivação para aprender e compreensão de leitura em alunos do ensino fundamental I. Estudos Interdisciplinares em Psicologia.

Field, A. (2009). Descobrindo a estatística usando o SPSS. Porto Alegre, Brasil: Artmed.

Garcia, N. R., \& Boruchovitch, E. (2014). Atribuições de causalidade para o desempenho escolar e resiliência em estudantes. Psico-USF, 19(2), 277-286.

Garcia, N. R., \& Boruchovitch, E. (2015). As atribuições de causalidade no ensino fundamental: Relações com variáveis demográficas e escolares. Psico, 46(2), 176187. doi:10.15448/1980-8623.2015.2.17642

Guimarães, S. E. R. (2009). A organização da escola e da sala de aula como determinante da motivação intrínseca e da meta aprender. In E. Boruchovitch \& J. A. Bzuneck (Orgs.), A motivação do aluno: Contribuições da Psicologia Contemporânea (pp. 78-95). Petrópolis, RJ, Brasil: Vozes.

Instituto Nacional de Estudos e Pesquisas Educacionais Anísio Teixeira. (2016). Brasil no PISA 2015: Análises e reflexões sobre o desempenho dos alunos brasileiros. Recuperado de http://download.inep.gov.br/ acoes internacionais/pisa/resultados/2015/ pisa2015 completo final baixa.pdf

Instituto Nacional de Estudos e Pesquisas Educacionais Anísio Teixeira. (2017). Sistema de Avaliação da Educação Básica - SAEB. Recuperado de https://medium. com/@inep/resultados-do-saeb-2017f471ec72168d

Kline, R. (2011). Principles and practice of structural equation modeling (3rd ed.). New York: Guilford Press.

Lohbeck, A., Grube, D., \& Moschner, B. (2017). Academic self-concept and causal attributions for success and failure amongst elementary school children. International Journal of Early Years Education, 25(2), 190203. doi:10.1080/09669760.2017.1301806

Martinek, T. J., \& Griffith, J. B. (1994). Learned 
helplessness in physical education: A developmental study of causal attributions and task persistence. Journal of Teaching in Physical Education, 13, 108-122.

Martini, M. L., \& del Prette, Z. A. P. (2005). Atribuições de causalidade e afetividade de alunos de alto e baixo desempenho acadêmico em situações de sucesso e de fracasso escolar. Revista Interamericana de Psicologia, 39(3), 355-368. Recuperado de https://dialnet.unirioja.es/servlet/ articulo? codigo $=2989470$

McClure, J., Meyer, L. H., Garisch, J., Fischer, R., Weir, K. F., \& Walkey, F. H. (2011). Students' attributions for their best and worst marks: Do they relate to achievement? Contemporary Educational Psychology, 36, 71-81.

Mijs, J. J. (2016). Stratified failure: Educational stratification and students' attributions of their mathematics performance in 24 countries. Sociology of Education, 89(2), 137-153. doi:10.1177/0038040716636434

Miranda, L., Almeida, L. S., Boruchovitch, E., Almeida, A., \& Abreu, S. A. (2012). Atribuições causais e nível educativo familiar na compreensão do desempenho escolar em alunos portugueses. Psico-USF, 17(1), 1-9. doi:10.1590/S1413-82712012000100002

Muthén, L. K., \& Muthén, B. O. (2012). Mplus user's guide: Statistical analysis with latent variables (7th ed.). Los Angeles, CA: Muthén \& Muthén.

Nascimento, S., \& Peixoto, F. (2012). Relações entre o estatuto escolar e o autoconceito, auto-estima e orientações motivacionais em alunos do 9..$^{\circ}$ ano de escolaridade. Análise Psicológica, 4(XXX), 421-434.

Neves, S. P., \& Faria, L. (2007). Auto-eficácia académica e atribuições causais em Português e Matemática. Análise Psicológica, 25(4), 635-652. doi:10.14417/ap.472

Osti, A., \& Martinelli, S. D. C. (2014).
Desempenho escolar: Análise comparativa em função do sexo e percepção dos estudantes. Educação e Pesquisa, 40(1), 4959. Recuperado de http://www.scielo.br/ pdf/ep/2013nahead/aop1200.pdf

Paiva, M. L. M. F., \& Boruchovitch, E. (2010). Orientações motivacionais, crenças educacionais e desempenho escolar de estudantes do ensino fundamental. Psicologia em Estudo, 15(2), 381-389. Recuperado de http://www.scielo.br/pdf/pe/ v15n2/a17v15n2

Paiva, M., \& Boruchovitch, E. (2014). Revisitando a teoria atribucional: Compreendendo as relações interpessoais em sala de aula. Itinerarius Reflectionis, 10(2). doi:10.5216/rir.v10i2.31195

Pereira, F. O. (2015). Especificidades do rendimento, aptidão e motivação escolares em alunos com dificuldades deaprendizagem. Psicologia Escolar e Educacional, 19(3), 525536. doi:10.1590/2175-3539/2015/0193889

Rosander, P., \& Bäckström, M. (2012). The unique contribution of learning approaches to academic performance, after controlling for IQ and personality: Are there gender differences?. Learning and Individual Differences, 22(6), 820-826. doi:10.1016/j. lindif.2012.05.011

Schwerdt, G., West, M. R., \& Winters, M. A. (2017). The effects of test-based retention on student outcomes over time: Regression discontinuity evidence from Florida. Journal of Public Economics, 152(C), 154169. doi:10.1016/j.jpubeco.2017.06.004

Stader, S. R., \& Licht, B. G. (1992). Effects of questionnaire administration condition on children's achievement-related beliefs. Journal of Educational Psychology, 84(1), 2834.

Suehiro, A. C. B., \& Boruchovitch, E. (2016). Compreensão em leitura em estudantes do terceiro e quarto ciclos do ensino 
fundamental. Psico-USF, 21(3), 561-572. doi:10.1590/1413-82712016210310

Urbina, S. (2007). Fundamentos da testagem psicológica. Porto Alegre, RS, Brasil: Artes Médicas.

Wagner, D. A., Spratt, J. E., Gal, I., \& Paris, S. G. (1989). Reading and believing: Beliefs, attributions, and reading achievement in Moroccan school children. Journal of Educational Psychology, 81(3), 383-293.

Weiner, B. (1986). An attributional theory of achievement motivation and emotion. In B. Weiner, An attributional theory of motivation and emotion (pp. 159-190). New York: Springer US.

Weiner, B. (2010). The development of an attribution-based theory of motivation: A history of ideas. Educational Psychologist, 45(1), 28-36. doi:10.1080/00461520903433596

Weiner, B. (2018). The legacy of an attribution approach to motivation and emotion: A nocrisis zone. Motivation Science, 4(1), 24-25. doi: $10.1037 / \operatorname{mot} 0000100$

Zambon, M. P., \& Rose, T. M. S. (2012). Motivação de alunos do ensino fundamental: Relações entre rendimento acadêmico, autoconceito, atribuições de causalidade e metas de realização. Educação e Pesquisa, 38(4), 965-980. doi:10.1590/S151797022012000400012

Zimmerman, B. J. (2013). From cognitive modeling to self-regulation: A social cognitive career path. Educational Psychologist, 48(3), 135-147. doi:10.1080/00 461520.2013 .794676
The Causality Attributions SCALE OF SCHOOL PERFORMANCE: A STUDY OF VALIDITY CRITERION EVIDENCE

\section{Abstract}

The aim of this study was to provide concurrent criterion validity evidence to the Causal Attributions Assessment Scale for Basic Education (EAVAT-EF). The school performance measures used were the students' scores in Portuguese Language and Mathematics and their self-evaluation of income in the school. 661 Brazilian's students from Elementary and Middle Schools in Brazil (3rd to 9th grades), of both genders, aged 8 to 17 years $(M=11.82, S D$ $=1.91$ ) participated in this study. The predictive model of school performance was based on EAVAT-EF factors added to the variables gender, number of previous school repetitions and self-evaluation. This model was tested in Elementary and Middle School. In Elementary School, the linear regression analysis showed that the EAVAT-EF factors had the explained variance less expressive for school performance compared to the standardized coefficients identified in Middle School. The intrapersonal causal attributions seem to interfere on the students' academic performance through classifications and students' self-evaluation, and vice versa. In addition, these results suggest that the impact on the causal attributions is consolidated and becomes more relevant with the advancement in schooling.

Keywords: Causal attribution; Motivation for learning; Basic Education; Psychoeducational assessment. 
Escala de Atribuciones de CAUSALIDAD Y RENDIMIENTO ESCOLAR: ESTUdiO DE EVIDENCIA DE VALIDEZ DE CRITERIO

\section{RESUMEN}

El objetivo de este estudio fue conferir evidencia de validez de criterio concurrente a la Escala de Evaluación de las Atribuciones de Causalidad para Alumnos de la Educación Básica (EAVAT-EF), teniendo como variable criterio el rendimiento escolar. Las medidas de rendimiento escolar utilizadas fueron los puntajes de los estudiantes en las disciplinas de Portugués y Matemáticas y su autoevaluación de los ingresos en la escuela. Participaron en este estudio 661 alumnos de escuelas públicas brasileñas de dos niveles de enseñanza de la Educación Básica (3..$^{\circ}$ al 9. año), de ambos gêneros, con edades entre 8 y 17 años $(M=$ $11,82 ; D P=1,91)$. El modelo de predicción del rendimiento escolar se constituyó por los factores de la EAVAT-EF agregado a las variables gênero, número de repeticiones escolares $y$ autopercepción de rendimiento. Este modelo fue probado para los dos niveles de enseñanza y funcionó sólo para el segundo nivel. En el primero nivel dela enseñanza, a través del análisis de regresión lineal, los factores de la EAVAT-EF tuvieron la varianza explicada menos expresiva para el rendimiento escolar en comparación a los coeficientes estandarizados identificados en el segundo nivel. Se considera que las atribuciones de causalidad tienen impacto en el rendimiento escolar evaluado por medio de las clasificaciones y de la autopercepción de rendimiento de los alumnos, y viceversa. Los resultados sugieren, además, que este impacto se consolida, haciéndose cada vez más relevante con el avance en la escolaridad.

Palabras clave: Atribución causal; Motivación para el aprendizaje; Enseñanza Básica; Evaluación psicoeducativa.

${ }^{\text {I }}$ Programa de Pós-Graduação Stricto Sensu em Psicologia, Universidade São Francisco, Brasil. Orcid: 0000-0002-9856-0094

${ }^{\text {II }}$ Programa de Pós-Graduação Stricto Sensu em Psicologia, Universidade São Francisco, Brasil. Orcid: 0000-0002-8599-7465

III Centro de Investigação em Educação (CIEd), Instituto de Educação, Universidade do Minho. Portugal. Orcid: 0000-00020651-7014 